\title{
Flexible cystoscope retrieval of detached resectoscope sheath beak
}

\author{
Jonathan Athayde, Frank Papanikolaou, MD, FRCPC ${ }^{2}$ \\ 'Western University, London, ON, Canada; ' $U n$ niversity of Toronto, The Hospital for Sick Children, and Trillium Health Partners, Toronto, ON, Canada
}

Cite as: Can Urol Assoc J 2017;11 (3-4):E124-5. http://dx.doi.org/10.5489/cuaj.4145

Published online March 16, 2017

\section{Introduction}

Surveillance cystoscopy for bladder cancer following transurethral resection of the prostate (TURP) can have unexpected consequences, such as the detachment of the resectoscope beak. This is an infrequent event, with few published or standard techniques for its retrieval. These techniques range from the use of forceps, as Grainger et al described in the first published case report on resectoscope sheath extraction, ${ }^{1}$ to the use a holmium YAG laser with a $200 \mu \mathrm{m}$ fiber to fragment the 26 French (Fr) resectoscope sheath in the patient's bladder and other laser-based techniques. ${ }^{2,3}$ We hypothesize that resectoscope beak extraction can be achieved efficiently and safely using a flexible cystoscope in the absence of a laser apparatus and with better postoperative results than rigid resectoscope or forceps for extraction. ${ }^{4}$

\section{Methods}

During surveillance cystoscopy following TURP, the plastic beak of a $24 \mathrm{Fr}$ resectoscope was incidentally found dislodged in the bladder of our patient. The patient did not have any symptoms related to the beak. Extraction with a 27 Fr resectoscope with stone grasper forceps was attempted, but was not successful. The urethra was then dilated to 30 $\mathrm{Fr}$, and the placement of an Amplatz dilator system with a nephroscope sheath was attempted, but did not succeed despite ample lubricant. The flexible Storz cystoscope was introduced once again into the urethra in order to retrieve the beak (Fig.1)

\section{Results}

The flexible scope was placed through the lumen of the plastic beak and then the cystoscope was pushed as far as possible into the bladder (Fig. 2). Once inserted, $5 \mathrm{~mm}$ flex- ible grasper forceps were put through the flexible scope with the beak on the proximal area and then were opened at the tip of the scope to act as a boundary (Fig. 3). This apparatus was then extracted without trauma to the urethra lumen and the patient did not report any postoperative complications due to the retrieval.

\section{Discussion}

The resectoscope beak detachment in the bladder is a rare and unexpected occurrence. It is difficult to remove due to its shape, as well as its smooth and rigid structure. Retrieval methods, such as the use of forceps for removal as suggested by Grainger et al, are, in our opinion, ineffective at retrieving detached sheaths. ${ }^{1}$ More modern techniques, such as the Holmium YAG laser used by Habermacher and Nadler $^{2}$ or the thulium laser used by Davis et $\mathrm{al}^{3}$ are effective, but increase the duration of the procedure significantly and require expensive and often inaccessible equipment. In the case of Davis et al, the thulium laser was necessary due to the calcification of the beak in the bladder. ${ }^{3}$ However, this was a unique case in which the discovery of the detached beak was a delayed rather than a perioperative correction. Techniques similar to the one we are proposing include the use of a rigid cystoscope with a $6 \mathrm{Fr}$ embolectomy balloon catheter, which is used to extract the sheath, ${ }^{5}$ or a rigid Storz 26 Fr continuous-flow resectoscope with a rollerball attachment to trap and extract the sheath. ${ }^{4}$ While both of these techniques are effective, they both employ the use of a rigid apparatus, which is more difficult, as well as traumatic and time-consuming to insert into the urethra. The use of a flexible cystoscope is a less invasive and more efficient method of retrieving detached resectoscope beaks.

Competing interests: The authors report no competing personal or financial interests.

This paper has been peer-reviewed. 


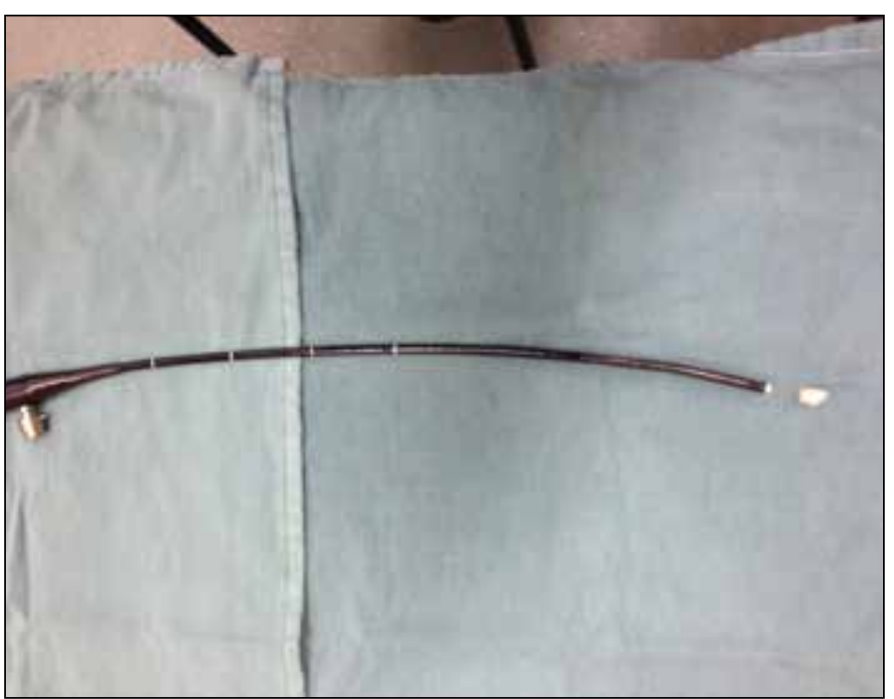

Fig. 1. Flexible Storz cystoscope and detached beak.

\section{References}

1. Grainger R, Coleman J, Walsh A. Preventable post-prostatectomy penile pain. Br J Urol 1988;61:457. https://doi.org/10.1111/j.1464-410x.1988.tb06599.x

2. Habermacher $G$, Nadler RB. Intravesical holmium laser fragmentation and removal of detached resectoscope sheath tip. J Urol 2005; 174:1296-7. https://doi.org/10.1097/01.ju.0000173916.33662.b7

3. Davis NF, McGuire BB, Flood HD. Delayed presentation of a detached resectoscope beak and treatment with thulium laser. Can Urol Assoc J 201 1;5:E17-8.

4. Hyunh CC, Ahmad NA, Woo H. Retrieval of detached resecroscope sheath beak during a TURP. Int Urol Nephol 2009;41:465-6.

5. Coker $C B$, Winkler $M$, Kapasi F, et al. Removal of a detached resectoscope insulating beak from the bladder. Br J Urol 1998;81:622. https://doi.org/10.1046/j.1464-410x.1998.00651.x

Correspondence: Mr. Jonathan Athayde, Western University, London, ON, Canada jathayde2019@meds.uwo.ca

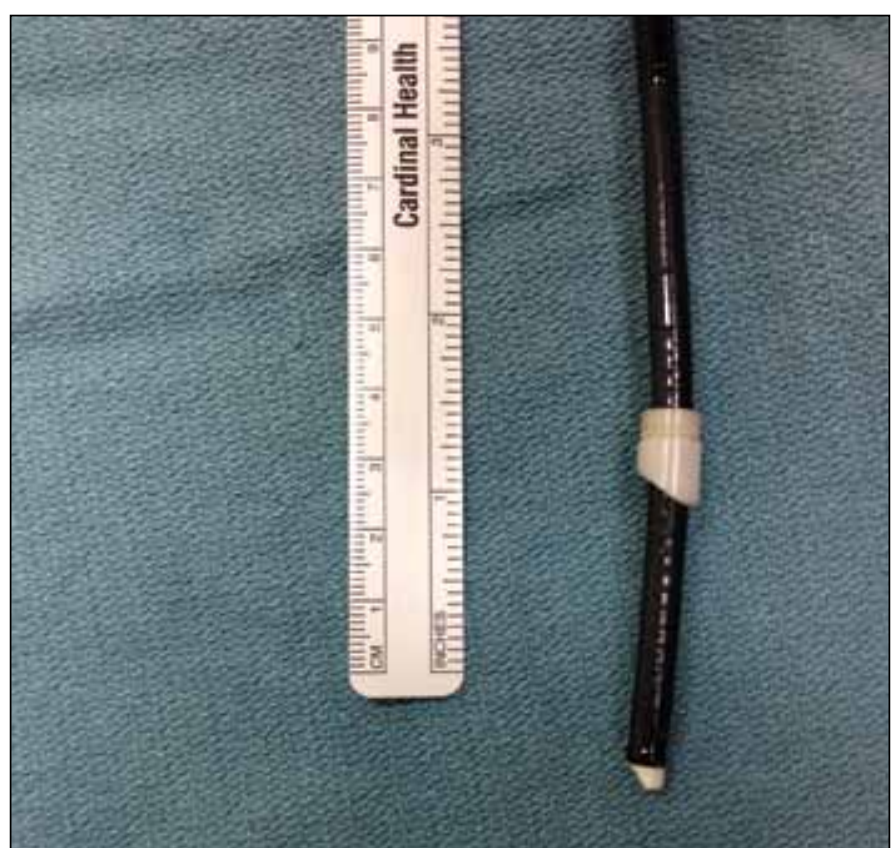

Fig. 2. Flexible scope placed through the beak.

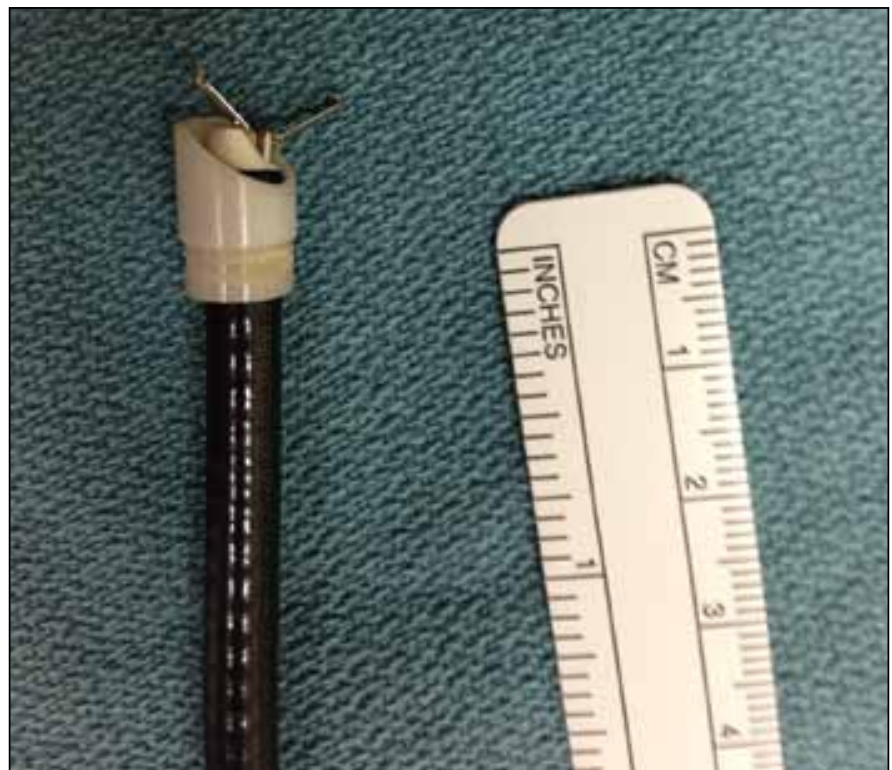

Fig. 3. Flexible grasper forceps placed through the flexible scope to trap the beak. 